\title{
Research on the Renewal and Reconstruction of Pingwu Old County Seat
}

\author{
Fang Xu \\ School of Architecture, Southwest Minzu University, Chengdu, China \\ Email: 2076347632@qq.com
}

How to cite this paper: $\mathrm{Xu}, \mathrm{F}$. (2021) Research on the Renewal and Reconstruction of Pingwu Old County Seat. Open Access Library Journal, 8: e7776.

https://doi.org/10.4236/oalib.1107776

Received: July 20, 2021

Accepted: August 6, 2021

Published: August 9, 2021

Copyright (C) 2021 by author(s) and Open Access Library Inc.

This work is licensed under the Creative Commons Attribution International License (CC BY 4.0).

http://creativecommons.org/licenses/by/4.0/

\begin{abstract}
China's urban planning has the characteristics of multi-field and multi-level, and the corresponding planning theories are also diversified, which can be applied to different situations. However, with the rapid development of China's economy, society and culture, the continuous increase of population and the high-speed urban construction, the problem of unbalanced urbanization process has emerged. Therefore, the renewal and reconstruction of the old city has become the general trend of the current urban construction and development. It is the key to urban construction and an unavoidable problem in the process of urbanization. It is related to the comprehensive development process of economy, culture and society of a city. How to carry out the renewal and reconstruction of the old city scientifically and rationally has brought great challenges to the city planners and builders. This paper takes the renovation of Pingwu old county seat as an example, and analyzes the location, historical evolution, important history, cultural relics, buildings and facilities of Pingwu old county seat according to existing data and field research, and based on the status quo of Pingwu and old city renovation, upgrading strategy is put forward, in order to contribute to Pingwu and city construction and development.
\end{abstract}

\section{Subject Areas \\ Urban Planning}

\section{Keywords}

Renovation and Reconstruction, Protection of Historical and Cultural Heritage, Harmonious Development, Enhance the Environment

\section{The Significance and Application Value of the Renewal of Old City}

The renewal and reconstruction of old cities have improved urban functions and 
raised people's living standards. In the old city, there are some problems such as narrow and crowded roads, dangerous and old houses, and inadequate infrastructure. Urban functions and infrastructure should be improved and the living environment quality of residents improved through the renewal and reconstruction of old cities [1].

Plan industries and accelerate the economic development of the old city. The historical and cultural sites of Pingwu should be used to develop tourism, drive the commercial development of the old city, and accelerate the pace of the old city reconstruction [2].

The reconstruction of Pingwu County old city is the inevitable requirement of its development, but there are still some problems in the process of reconstruction. Based on the actual situation of Pingwu County, this paper mainly studies the problems of old city renewal and reconstruction, and proposes solutions to provide reference for the old city renewal and reconstruction work in Pingwu County [3].

\section{Interpretation and Current Situation Analysis of Pingwu Old City}

\subsection{Historical Development}

Pingwu County Town, county resident. Ping An Town in 1940, 1954 to Chengguan Town, 1981 renamed Long'an Town, including West Street, Bao'en Temple, Government Street, People’s East Road, 4 neighborhood committees.

\subsection{Pingwu Old County Seat of Important History and Cultural Relics}

There are many key cultural relics protection units in Pingwu old county, among which Bao'en temple (Figure 1) is the national key cultural relics protection unit, and West gate and city wall are the provincial key cultural relics protection units.

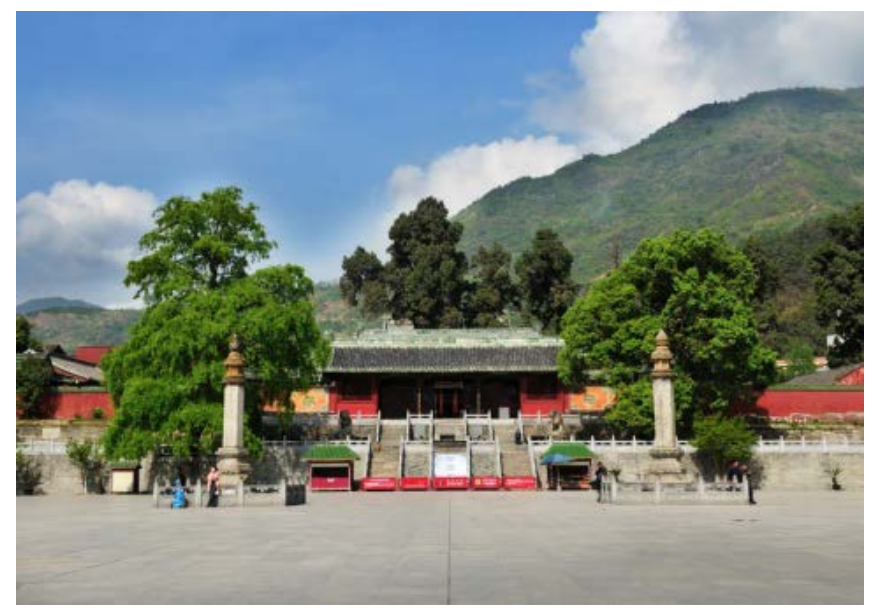

Figure 1. Bao'en Temple (source of the picture:

https://baike.baidu.com/item/\%E6\%8A\%A5\%E6\%81\%A9\%E5\%AF\%BA/5618062?fr=alad din). 
Located in Long'an Town, Pingwu County, it was built in the fifth year of the Ming Dynasty and completed in the fourth year of Tianshun in the Ming Dynasty. It is known as "a rare relic of the early Ming Dynasty and a masterpiece with unique originality". It is one of the largest ancient architectural complexes of the Ming Dynasty in Sichuan Province and the best preserved in China. The whole temple covers an area of more than 27,800 square meters, with a building area of 3500 square meters. The temple has a large scale and rigorous layout, integrating architecture, sculpture, painting and other arts as one, and integrating the great achievements of Confucianism and Buddhism culture. Now it is a national key cultural relic protection unit, a teaching and scientific research base of the School of Architecture of Tsinghua University, and a national AAAA level tourist attraction [4].

West the gates and the wall is the provincial-level key cultural relics protection units, Ming Xuande five years to build, in the early days after foundation, Long An government walls, gates, towers, yamen, official residence in the city, homes and part of the better preserved ancient architecture, such as religious temples between 1956 and 1974, because of natural disaster and man-made destruction, most of the traditional buildings were damaged. The main purpose of urban layout in this era was to strengthen military defense. The city is surrounded by the wall built by the back mountain and the water, and the gate is close to the Fu River, using the steep terrain of the high and low, and the way is inclined to form a solid fortress.

At present, only the west gate (Figure 2) and the ancient city wall (Figure 3) remain. Due to severe weathering and some damaged places, cultural relics need to be protected.

\subsection{Analysis of the Present Situation of the Od County}

\subsubsection{Current Building Overview}

The most local characteristic of Pingwu residential buildings is the ancient buildings with local characteristics. In the construction of materials, form, volume has

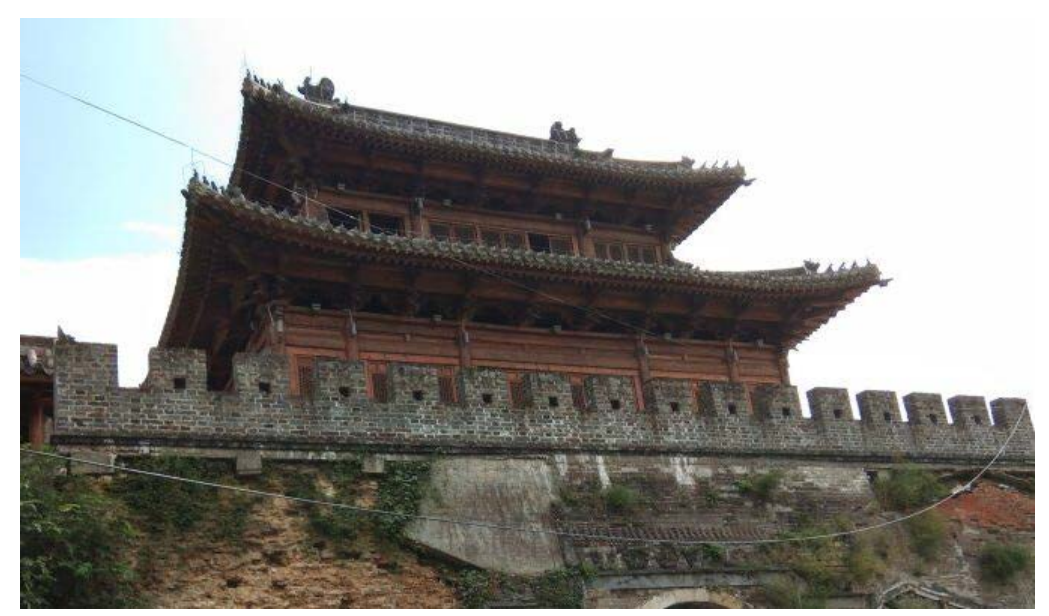

Figure 2. West Gate (source of the picture: the author shot). 


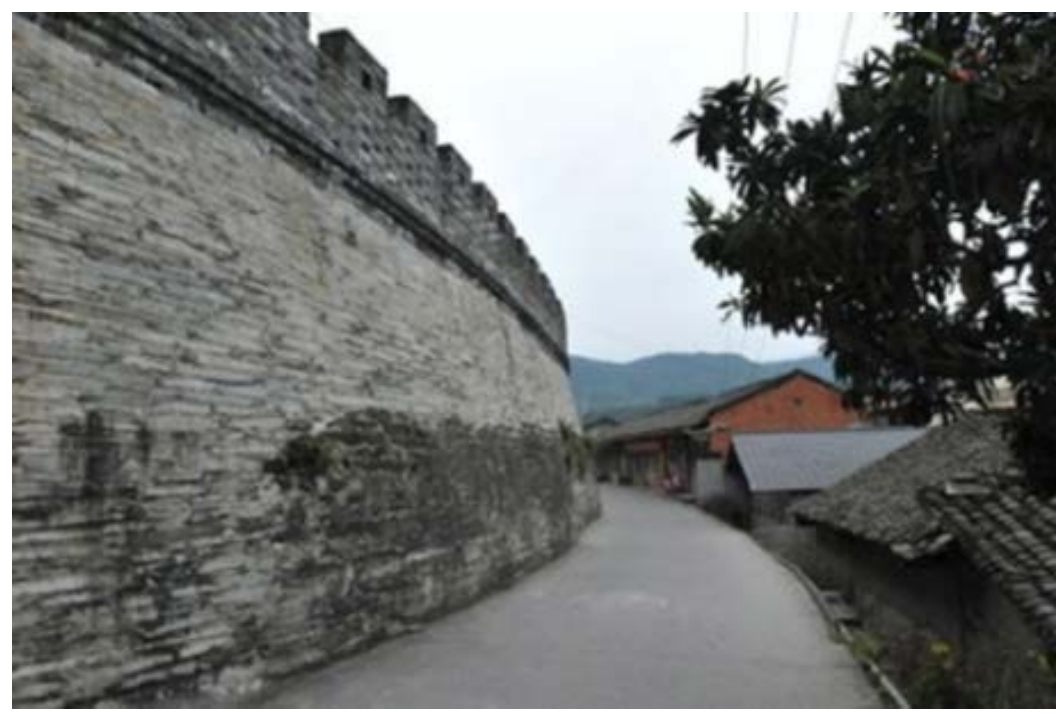

Figure 3. Ancient City Wall (source of the picture: the author shot).

a unique style. From the current situation, the houses around the temple are mostly wooden buildings with characteristics, but the construction quality is poor. The buildings in other areas are brick and wood, civil buildings and simple structure tile roofing houses, which are "old, broken, dirty, messy and poor", which are their common characteristics.

1) Current building height

In the old city, the building height is mainly multi-storey buildings, small high-rise and low-rise buildings are relatively few. The height of the building is mostly controlled at $12-24 \mathrm{~m}$ (Figure 4).

2) Current building quality

In the old city, Bao'en Temple and the old city wall are the core historical and cultural protection buildings, and their architectural quality is relatively good, while the waterfront area and the Bao'en Temple block construction quality is poor.

3) The age of the building

In the plot, the architectural span is relatively large, there is the Ming Dynasty architecture-Bao'en Temple, after the founding of the People's Republic of China to the 1980s, and there are modern buildings (mostly residential communities). Bao'en temple area has a rich atmosphere of historical relics.

4) Current architectural features

In the plot, the architectural style is not coordinated and unified, and the architectural style around the Bao'en Temple and the old city wall is chaotic. The ancient buildings are mixed with some modern high-rise buildings, resulting in the architectural form of the two cultural relics protection units is incompatible.

\subsubsection{Current Public Service Facilities}

In the plot, the public service facilities mainly include the community committee, Pingwu County Hospital, Long'an Town Association for the elderly, library, 

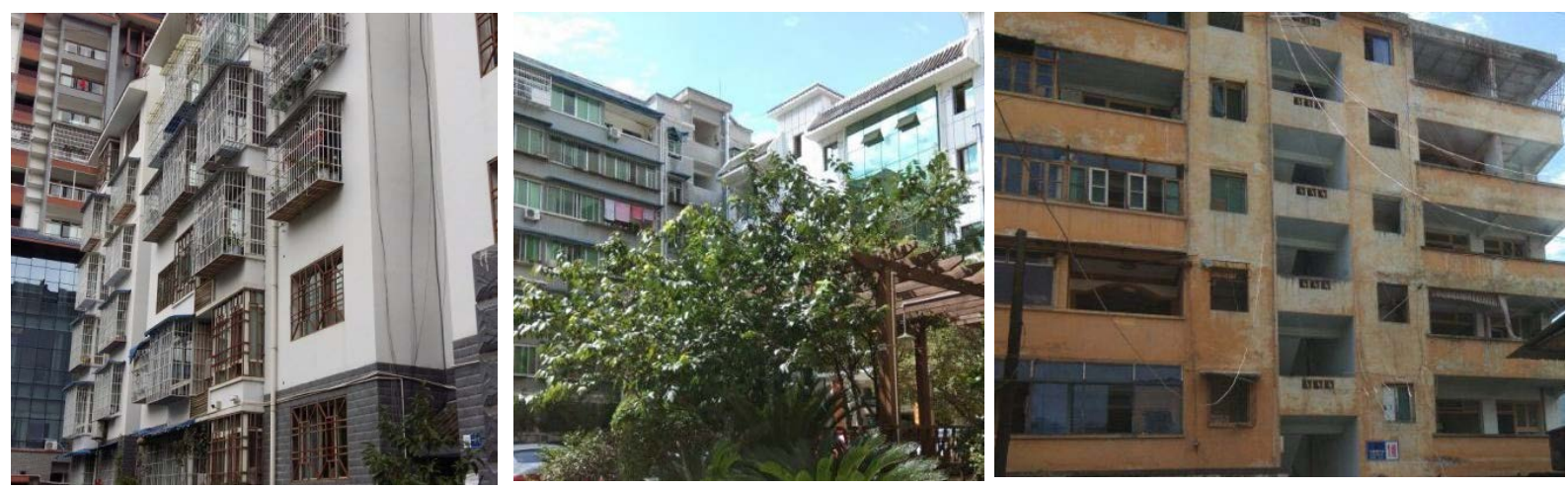

Figure 4. Status quo of the construction (source of the picture: the author shot).

emergency command center, cultural venues, Long'an Kindergar10, Qiyi Fu River Primary School, Beishan Primary School and wholesale market. In terms of distribution, the county's public service facilities are concentrated in the vicinity of North street and Bao'en Temple Street, with uneven distribution and relatively single type.

\subsubsection{Analysis of Environmental Elements}

The area of Bao'en Temple in Long'an Town of Pingwu County is located in the landform area of the Fu River Valley. The terrain slopes from the northwest to the southeast, surrounded by mountains around the county seat, Fu River around the knee, relatively flat terrain. The region has a mild climate, a forest coverage rate of more than $45 \%$, a rich and diverse geological structure, and a unique natural environment. Most of the area is Fu River alluvial flat dam, good geological conditions, but because of the mountains, in addition to the alluvial flat dam, the county's surrounding land slope is larger, the land resources along the Fu River strip distribution shape, land resources are poor.

\section{The Existing Problems of Pingwu Old County}

1) The features of the old area are missing. The Bao'en Temple and the old city wall of the West Gate are the historical and cultural protection points of the old Pingwu County, but the surrounding buildings are of poor quality, with different architectural styles and disordered layout, and the new buildings lack cultural characteristics. Part of the old city buildings in dilapidated conditions, part of the dilapidated state, lost the vitality of the ancient city.

2) Along the area of Fu River lack of landscape planning, no characteristics, public service facilities are not perfect, poor environmental quality.

3) The government and local residents have not reached a harmonious and consistent communication. The demolished area still has dilapidated houses, and some residents are unwilling to move. The traditional spatial pattern of the ancient city has been destroyed in terms of spatial texture and scale [5], leading to many problems such as ecological environment, road traffic, landscape style and tourism development [6]. 
4) The public participation is not enough. The original residents are the most numerous group in the old city renewal and reconstruction, and they are also the vulnerable group in the demolition. Due to the lack of participation, some residents and the government have not reached a consensus, and the demolition has not been completed.

5) The urban road does not conform to the standard, the urban road network is not perfect, the old city road system is chaotic, the east-west Feilong Road and the north-south South Street and North Street are the urban main road, but the road width is not enough, the environment is poor, the lack of road greening on both sides, the traffic organization is inconvenient. Branch roads are not system, narrow streets and lanes; The parking lot is seriously insufficient and the phenomenon of occupied parking is serious. Public transport lags [2].

6) There are no commercial streets with regional characteristics planned in Long'an Town. Most of them are ordinary shops along the streets. The market is also chaotic and there is a lack of commercial complexes.

7) The old city has no systematic open space and lacks infrastructure. Sanitation, culture, sports, fire and other public facilities and municipal supporting facilities are insufficient [2].

\section{Pingwu Old City Renewal and Reconstruction Measures}

\subsection{The Renewal of Old Cities and the Development of Historical and Cultural Reserves Are Coordinated}

Bao'en Temple, the ancient city wall is Pingwu existing historical and cultural buildings. According to the overall planning of Pingwu, the historical buildings are protected to effectively renovate the environment of historical blocks, and the historical culture is protected as a whole, so as to achieve the effect of sustainable development of society, economy and culture.

\section{Specific measures:}

1) Protection of the periphery pattern of historic urban areas: focus on the protection of the landscape pattern of "one river, two sides, north and south mountains", and prohibit the destruction and blocking of the landscape pattern of historic urban areas.

2) Protecting the pattern of streets and alleys in historic urban areas: Protecting the cross street and alleys structure composed of Feilong Road, North Street and South Street; Preserve the existing incomplete "Four Alleys and Fourteenth Streets" composed of West Street, Long'an Road, East Street, Bao'en Temple Street, and Hongxing Street.

3) Preserve the length of the original street space in the historic city

Landscape coordination area: urban construction activities should reduce the damage to the natural environment and landscape of mountains and rivers, strictly control the building volume and height of historic urban areas along the river, and coordinate with the city's traditional features and landscape.

Key control area: the potential area on both sides of Fu River should be con- 
trolled. The style and volume should be coordinated with the city's traditional style and landscape. It is strictly prohibited to build high-rise buildings in this area.

Historic urban areas: focus on protecting the urban pattern, style, height, line of sight corridor of the historic urban areas, actively carry out the renewal and improvement of land use, road network, municipal facilities, so as to make the traditional style and modern life better integration.

Historical and cultural blocks: protect cultural relic units, historical buildings, historical sites and other historical environment elements in strict accordance with national and local standards, and maintain the original spatial structure, streets and alleys and other historical landscape features.

\subsection{The Landscape Design}

The construction of the riverside green landscape belt running through the east and west of the city along the Fu River connects the main landscape nodes, public open space, public green space and other landscapes in the city.

Core landscape area: as the core landscape area of the city, Bao'en Temple, with the center of RT Mart as the center, is arranged with street commerce, radiating the whole old city area. Add square, green space and other activity places and perfect commercial services, cultural entertainment and other facilities, while shaping the landscape image features with their own characteristics.

Central area of old city: focus on Bao'en temple, west gate outside, South Gate outside and Ming city wall, organize urban activities with Feilong Road, South Street, North Street and West Street as skeleton, increase commercial and cultural facilities from west to south, optimize urban landscape, and form the best place for various activities, exchanges and tourism.

Public space node: Build Bao'en Temple Square, central green space, leisure park, etc.

\subsection{The Renewal and Renovation of Old Cities Will Develop in a Coordinated Way with the New Urban Areas}

From the perspective of space, the renewal and reconstruction of old cities is not one-sided and isolated, but often interdependent with urban space expansion [1]. Currently, Pingwu and old city renewal and reconstruction of the problem to be solved mainly solve the problem of relocation of residents, do public participation, play to the functions of government, combining new area construction, public services and infrastructure, the reasonable planning for the development of the new motive force and thrust, on the other hand, with the continuous development of new and growing, It can provide space and undertake capacity for population migration in the process of old city renewal and reconstruction, and promote the pace of old city renewal and reconstruction.

Specific methods and strategies for the coordinated development of old city renewal and reconstruction and new urban areas: 
1) Policy

a) Urban construction policy

In terms of the old city, reasonable development policies should be formulated to build the old city into an urban core area with diverse cultural facilities, prosperous commercial services and harmonious coexistence of nature and humanity [7].

b) Demolition and resettlement policies

In the development of real estate in the old city, the developer is required to convert the demolished households into the corresponding building area according to the number of people in their household registration book or the area of the demolished houses according to a certain proportion, and make compensation after the completion of the project; If the government lacks financial subsidies, the developers of new buildings must first compensate for the demolition area or settle the original population, and then a part of the area should be used to offset the construction cost of the building, and the remaining area should be used as the developer's profit area [8].

2) The economy

a) Multiple financing to reduce the burden

The development of the project will drive the development of the land, carry out rolling development, and give play to the maximum value-added effect of the land [2].

b) A variety of channels to accumulate funds for infrastructure construction

In terms of government management, the market-oriented development of infrastructure should be actively explored, and various incentives and preferential policies should be adopted to encourage real estate developers to complete the supporting construction of part of infrastructure. Secondly, a scientific and reasonable land price evaluation system and method should be established to determine the reasonable development intensity according to the specific situation of various plots [2].

Old city renewal and reconstruction is affected by various factors and lasts for a long time. Therefore, it is necessary to adhere to the renewal and reconstruction goals for a long time. The formulation of overall planning cannot guarantee the smooth implementation of renewal and reconstruction. In the process of renewal and reconstruction, the reconstruction should first focus on the key areas. Combined with the situation of Pingwu, the renewal and reconstruction of the old city should pay attention to the following key areas:

The central part of the old city: renovate both sides of Feilong Road, West Street, South Street, North Street and Bao'en Temple Street in the old city, protect the traditional street pattern, maintain the public character of the ground floor buildings, and become an important part of the commercial center in the central district.

Continue to deepen the old city of Fu River landscape renewal and transformation, increase cultural entertainment and leisure and commercial facilities, 
create a comfortable leisure and open space along the river, the riverside area will be transformed into a continuation of the urban context and shaping the main space carrier of urban characteristics.

The city wall and the west gate section: to be built into a riverside leisure and entertainment area integrating historical and cultural display, traditional folk leisure and riverside view.

Bao'en Temple and surrounding areas: the temple and surrounding areas are built to form a historical tourist district with Bao'en Temple as the core, which is a collection of cultural sightseeing and leisure and entertainment.

Along Feilong Road, Bao'en Temple Street and other main roads along the city landscape building, beautification of the road environment along the road, the transformation of municipal facilities and street buildings on both sides of the style renovation, enhance and beautify the old city main passage, the new city characteristic public space.

\subsection{Combine "Retention, Renewal and Reconstruction" to Build a New Pattern of Old Urban Areas}

In the renewal of the old city, it is suggested to retain historical buildings and blocks with local characteristics, protect the characteristic features of the old city, and strictly control the intensity and form of surrounding construction. Areas with concentrated construction and complete features shall be updated and demolished appropriately. For the areas where the current buildings are scattered and of poor quality, the method of demolition and reconstruction shall be adopted [9].

Through the development mode of "reservation, renewal and reconstruction", the new pattern of old city area is constructed, the new image of old city is created, the new charm of old city area is excavated, and the core value of the old city can be exerted [10].

\section{Based on the Current Situation of Pingwu Old City Renovation Thinking}

As a poverty-stricken county at the provincial level and a comparison county for ethnic minorities, Pingwu should develop comprehensively and harmoniously in the process of old city renewal and reconstruction, actively encourage multi-party participation, develop tourism with abundant tourism resources, attract investment by relying on existing resource advantages, promote local economic development with introduced enterprises, and improve residents' quality of life. Relevant government departments attach great importance to urban greening, vigorously regulate the environment, improve the level of greening, improve the level of urban management; We will pay attention to infrastructure construction and improve urban service capacity.

Old town renewal transformation involves the local government, developers and villagers in the process of the three common interests of all the good wishes 
to all need based on the interests of the game, in the entire process of construction of old update should accurately grasp the local government, enterprises, villagers dynamic balance, to the mutual benefit of the three regional economic value of the modified to increase greatly.

\section{Conclusions}

Urban environment is a complex and huge system with dynamic changes. The renewal and reconstruction of old cities is a process of constant exploration. With fixed templates, cities with different economic, social and cultural backgrounds adopt different renewal and reconstruction methods. Therefore, urban development can only be achieved through continuous exploration and dynamic changes according to local conditions and various limiting factors, and through the formulation of renewal and transformation planning schemes. In the process of formulating the planning scheme, various aspects such as economy, society, culture, population, spatial structure, environment, style and characteristics should be considered, and multiple disciplines such as geography, science, sociology, economics, architecture, aesthetics should be integrated to achieve the cross-discipline and design each field [11].

In view of the current trend of urbanization in China, the characteristics of urban renewal have become increasingly prominent, and the current urban planning issues have become more complex. In addition to taking protective measures for traditional architectural design and spatial forms, communication and coordination with the public and formulation of relevant policies by the government should also be considered. Various ideas of urban development have been put forward continuously, and the technical level of urban planning has been improved. The ultimate goal is "how to create better urban environmental quality".

Therefore, the most important goal of the renovation of Pingwu old county seat is to improve environmental quality, promote industrial development, drive economic growth, strengthen construction management, protect historical heritage, coordinate the development of all parties, and carry out constant reflection and reference in practice.

\section{Acknowledgements}

This paper is carried out based on the research materials of the course "Urban Renewal of Pingwu Old County". Thanks to the support of the research team members.

\section{Conflicts of Interest}

The author declares no conflicts of interest.

\section{References}

[1] Ni, H. (2006) Thinking on the Revision of Shenzhen Urban Planning Standards and Guidelines. Tongji University, Shanghai. 
[2] Liu, Z. (2009) Ganzhou Old City Renovation. Jiangxi University of Science and Technology, Ganzhou.

[3] Yang, X. (2019) Urban Design of Pingwu Old City under the Concept of "Urban Repair”. Southwest University of Science and Technology, Mianyang.

[4] Cao, H. (2017) Sichuan Pingwu County Gratitude Culture Seminar Held Experts and Scholars Feel the Pulse on the Spot. http://www.sc.chinanews.com/bwbd/2017-05-27/69670.html

[5] Zhang, D. (2013) Analysis on the Planning and Design of New Urban Area-Taking Hedong New Town of Liaoyang as an Example. Journal of Shenyang Jianzhu University (SOCIAL SCIENCE EDITION), 15, 23-26.

[6] Zhu, B. (2003) Analysis of Urban Space Expansion in Hangzhou. City Planning Review, No. 5, 89-92+98.

[7] Li, Q., Tang, Q., Jiang, X., Zhu, J. and Zhao, Q. (2013) Focus on the "Break" and "Stand" of Urban Construction. Masses, No. 7, 81-83.

[8] Zeng, S. (2013) On Old City Reconstruction and Land Optimization. Research on Urban Construction Theory(Electronic Version), No. 16, 1-3.

[9] Gao, W. (2017) Research on Two-Way Selection Mode of Dual Attribute Historical and Cultural Block Development. Chongqing University, Chongqing.

[10] Wang, J. (2019) Old City Renewal Strategies and Suggestions in the Old Urban Area of Ruijin City. Smart City, 5, 15-16.

[11] Liu, F. (2006) Spatial Location Evolution of Urban Residential Areas Driven by Market Force and Administrative Force. Tongji University, Shanghai. 